\title{
Early Surgical Closure of Atrial Septal Defect Improves Clinical Status of Symptomatic Young Children with Underlying Pulmonary Abnormalities
}

\author{
Takeshi Tsuda $^{1}$ (D) Ryan R. Davies ${ }^{2} \cdot$ Wolfgang Radtke $^{1} \cdot$ Christian Pizarro $^{2} \cdot$ Abdul M. Bhat $^{1}$
}

Received: 1 January 2020 / Accepted: 23 April 2020 / Published online: 9 May 2020

(c) Springer Science+Business Media, LLC, part of Springer Nature 2020

\begin{abstract}
Elective closure of atrial septal defect (ASD) is usually recommended during preschool ages. However, ASD may contribute to deteriorating health in the presence of significant comorbidity and, thus, may need earlier closure. There is a lack of clarity regarding the indications for and outcomes after ASD closure in infancy and early childhood. We investigated the benefits and safety of surgical ASD closure in symptomatic patients under 2 years of age. Retrospective chart review was conducted in patients who underwent surgical ASD closure within the first 2 years of life. Of 31 symptomatic ASD patients, 22 had persistent respiratory symptoms, 24 failure to thrive, and 9 pulmonary hypertension. Overall, 26 patients (84.0\%) showed clinical improvement after ASD closure, including improved respiratory status (17/22; 77.3\%), resumption of normal growth $(15 / 24 ; 62.5 \%)$, and resolution of pulmonary hypertension $(7 / 7 ; 100 \%, 2$ patients unable to assess postoperatively). Two medically complicated patients died a few months after surgery unrelated to surgical complications. Four out of 8 ventilator-dependent patients were weaned from mechanical ventilation within 1 month after ASD closure. Closure of ASD did not improve those patients with highly advanced lung disease and/or medically complex conditions including underlying genetic abnormalities. Surgical complications were uncommon. Postoperative hospital stay was 4 to 298 days (median 8 days). The majority of our patients demonstrated significant clinical improvement after ASD closure. Early ASD closure is safe and beneficial for symptomatic infants and young children with associated underlying pulmonary abnormalities, especially bronchopulmonary dysplasia.
\end{abstract}

Keywords Atrial septal defect (ASD) · Bronchopulmonary dysplasia (BPD) · Failure to thrive (FTT) · Respiratory distress · Congestive heart failure $\cdot$ Pulmonary hypertension

\section{Introduction}

Atrial septal defect (ASD) is the second-most common congenital heart disease presenting during childhood and is defined as an anatomical deficiency of the atrial septum. Clinical manifestations of ASD are primarily attributed to persistently increased pulmonary blood flow and dilated right atrium (RA) and right ventricle (RV) due to volume

Takeshi Tsuda

ttsuda@nemours.org

1 Nemours Cardiac Center, Division of Cardiology, Nemours/ Alfred I. duPont Hospital for Children, 1600 Rockland Rd., Wilmington, DE 19803, USA

2 Nemours Cardiac Center, Divisioin of Cardiothoracic Surgery, Nemours/Alfred I. duPont Hospital for Children, 1600 Rockland Rd., Wilmington, DE 19803, USA overload [1]. Despite markedly increased pulmonary blood flow, patients with ASD rarely become symptomatic or develop pulmonary vascular obstructive disease until midadulthood [2]. Traditionally, patients have been referred for ASD closure during childhood, before school-age, to prevent later complications [2,3].

Early closure of ASD during infancy has been historically more controversial. Occasionally, an isolated ASD may be associated with congestive heart failure in infancy, and the early closure appears to be beneficial [4-6]. In addition, patients with underlying pulmonary abnormalities including lung disease related to prematurity, bronchopulmonary dysplasia (BPD), or chronic aspiration may be adversely affected by increased pulmonary blood flow, and some have advocated early ASD closure to improve outcome in these patients [7]. However, the potential for spontaneous closure has led others to recommend conservative medical 
management even for symptomatic ASD in young children [8-10]. The historical concern with high surgical morbidity and mortality among infants with ASD and complex comorbidities [5] may no longer be applicable [7]. There is a lack of clarity regarding the indications for and outcomes after ASD closure in infancy and early childhood.

Percutaneous ASD device closure has become a standard option for asymptomatic older children and adults with secundum ASD [11]. However, its indication in infants and small children may be limited because of underlying ASD anatomy (defect too large, sinus venosus type or primum type ASD, deficient rim, multiple defects, and aneurysmal septum), small left atrium, and small size of an access vessel [12-14]. Surgical ASD closure is frequently indicated for those who are not amenable to the device closure and those who are clinically deteriorating despite maximum medical support, especially in infants and young children with known comorbidity.

The purpose of this study is to assess the benefits and safety of surgical ASD closure in symptomatic young children with significant clinical symptoms. We reviewed our institutional experience with symptomatic ASD patients who underwent surgical closure within the first 2 years of life. We retrospectively examined the clinical course and outcome after early surgical ASD closure and discuss the rationale of early surgical ASD closure in symptomatic young children.

\section{Methods}

\section{Patients}

A retrospective chart review was conducted in symptomatic patients with isolated ASD who underwent surgical ASD closure before 2 years of age at Nemours Cardiac Center, Nemours/Alfred I. duPont Hospital for Children, between January 1998 and December 2018. The study was approved by the Institutional Review Board of the hospital. Patients with ASD and either a small patent ductus arteriosus (PDA), partially anomalous pulmonary venous connection (in the setting of a sinus venosus ASD), or bicuspid aortic valve without significant hemodynamic abnormalities were included, whereas patients with other major concomitant congenital cardiac anomalies were excluded. Anatomical diagnosis was made primarily by echocardiogram. Inclusion criteria of "symptomatic" patients were based on the following definitions. The respiratory symptoms included: (a) the presence of baseline respiratory distress (tachypnea, retraction, hypoxia, apnea, increased work of breathing, or feeding difficulty); (b) persistent dependency on respiratory support including supplemental oxygen, continuous positive airway pressure (CPAP), or positive pressure ventilation; or (c) recurrent respiratory illness requiring hospitalization at least twice a year. The respiratory symptoms were divided into two groups: (1) "severe" (ventilator-dependent) and (2) "mild to moderate" (spontaneous breathing). Failure to thrive was defined as either (a) persistent low weight below 3 standard deviations (SD) from the mean value for age without improvement or (b) suboptimal weight gain falling below a standard growth curve (growth charts by Centers for Disease Control and Prevention, 0 to 36 months: www.cdc. gov/growthcharts/). Pulmonary hypertension was defined as either (a) estimated RV pressure by tricuspid regurgitation (TR) jet measurement by echocardiogram exceeding $2 / 3$ of simultaneous systemic pressure, or cardiac catheterization findings of (b) mean pulmonary arterial pressure (MPAP) $>25 \mathrm{mmHg}$, (c) pulmonary vascular resistance (Rp) $\geq 3.5 \mathrm{U} \cdot \mathrm{m}^{2}$, or (d) pulmonary vascular resistance/systemic vascular resistance $(\mathrm{Rp} / \mathrm{Rs})$ ratio $\geq 0.3$.

All patients were evaluated by our interventional cardiologist for possible percutaneous device closure before surgery, including patient size (weight) and transthoracic or transesophageal echocardiography to assess anatomy with particular attention to the size of the atrial septal rims in relation to the anticipated size of the ASD closure device. Those patients who underwent percutaneous ASD device closure were not included in this study.

\section{Surgical Technique}

Closure of ASD was performed via full or partial median sternotomy using cardiopulmonary bypass at mild hypothermia. Closure was performed using a patch of polytetrafluoroethylene (PTFE), Dacron, or autologous pericardium or by primary suture at discretion of the surgeon.

\section{Outcomes}

Clinical improvement in respiratory symptoms was defined as (a) resolution of respiratory symptoms, (b) withdrawal from positive pressure ventilation or supplemental oxygen within 1 month, or (c) freedom from recurrent respiratory illnesses requiring hospital admission. Improvement in growth was defined as a more than $1.0 \mathrm{z}$ score increase in standard growth chart (weight-for-age percentiles: birth to 36 months in each sex) within one year after ASD closure. Improvement in pulmonary hypertension was defined as a reduction of estimated pressure gradient of TR jet by continuous wave Doppler becoming less than half systemic blood pressure within 6 months after the ASD closure.

\section{Statistical Analysis}

The data are shown as mean \pm SD unless indicated otherwise. The comparison of the two groups was performed by 
two-tailed Student's $t$ test, and $p$ value of less than 0.05 was considered statistically significant.

\section{Results}

\section{Clinical Profile of the Recruited Patients}

Table 1 summarizes the clinical profile of 31 patients who underwent surgical ASD closure in the first 2 years of life for one or more of the followings: respiratory symptoms $(n=22)$, failure to thrive (FTT) $(n=24)$, or pulmonary hypertension $(n=9)$. The majority of patients had secundum type ASD $(26 / 31 ; 83.9 \%)$ with female predominance $(19 / 31 ; 61.3 \%)$. Commonly associated clinical conditions were prematurity/BPD $(11 / 31 ; 35.5 \%)$ and trisomy $21(6 / 31$; $19.4 \%)$. Ten patients underwent preoperative hemodynamic assessment by cardiac catheterization (Table 2). The ratio of total pulmonary blood flow to total systemic blood flow (Qp/Qs) was less than 2 in 6 patients and higher than 2 in 4 patients. Six patients were diagnosed as having pulmonary hypertension by cardiac catheterization (MPAP $>25 \mathrm{mmHg}$,

Table 1 Patients who underwent ASD closure before 2 years of age $(n=31)$

\begin{tabular}{ll}
\hline & Patients $(n=31)$ \\
\hline Age of surgery & $49-409$ days $(231 \pm 154)$ \\
M:F & $12: 19$ \\
Anatomy & \\
Secundum & 26 \\
Sinus venosus & 3 \\
Secundum and sinus venosus & 1 \\
Primum & 1 \\
Other cardiac/hemodynamic anomalies & \\
PDA (small) & $7(4$ previously closed) \\
PAPVR & 1 \\
Aortic arch hypoplasia (mild) & 2 \\
Pulmonary hypertension & 9 \\
Underlying conditions & \\
Prematurity/BPD & 11 \\
Trisomy 21 & 6 \\
Pierre-Robin sequence & 2 \\
Chromosome 3/4 translocation & 1 \\
1p36 deletion & 1 \\
Kabuki syndrome & 1 \\
CODAS syndrome & 1 \\
Congenital CMV infection & 1 \\
Unknown multiple congenital anomalies & 2 \\
\hline
\end{tabular}

$P D A$ patent ductus arteriosus, $P A P V R$ partial anomalous of pulmonary venous return, $B P D$ bronchopulmonary dysplasia, CODAS syndrome cerebral, ocular, dental, auricular, skeletal syndrome (MIM 600,373), $C M V$ cytomegalovirus
$R_{\mathrm{p}} \geq 3.5 \mathrm{U} \mathrm{m}^{2}$, or $\left.R_{\mathrm{p}} / R_{\mathrm{s}} \geq 0.3\right)$. None had a right to left shunt. Pulmonary vasodilators were tested in 6 patients. Four patients responded to increased inspired oxygen and nitric oxide with either increased $Q_{\mathrm{p}} / Q_{\mathrm{s}}$ or decreased $R_{\mathrm{p}} / R_{\mathrm{s}}$, whereas 2 patients showed minimum response (Pts 10 and 14). Of note, Pt 14 was found to have associated functional left pulmonary vein stenosis by cardiac catheterization.

\section{Surgical Approach and Complications}

Surgical procedures and postoperative complications are listed in Table 3. Complications were relatively limited. A total of 4 patients had a patch with fenestration. Total hospital stay after the surgery was 4 to 298 days (median 8 days). The incidence of significant pericardial effusion that required medical treatment (steroids or ibuprofen) and/or pericardiocentesis was $2 / 31$ (6.5\%). Postoperative mortality was $2 / 31(6.5 \%)$, although both deaths occurred late after surgery (108 and 145 days) and were unrelated to the surgical procedure or postoperative complications (Pts 15 and 21). One additional patient (Pt 16) died 6 years after surgery with unimproved respiratory status (Table 4).

\section{Clinical Improvement after ASD Repair}

Clinical improvement in any of 3 categories was noted in 26/31 (83.9\%) in our cohort.

\section{Respiratory Symptoms}

Twenty-two patients (71.0\%) had variable degrees of respiratory symptoms (Table 5). Eight patients were classified as "severe" because of their ventilator-dependent chronic respiratory failure with multiple underlying medical problems; 5 patients were ventilated via endotracheal tube, and the other 3 were via tracheostomy. Two patients, Pts 16 and 21, underwent tracheostomy 9 and 3 months after ASD closure, respectively. Five patients had BPD, and 5 patients had underlying genetic abnormalities including trisomy 21 (2 patients) and Pierre-Robin sequence ( 2 patients). Four of 8 patients were successfully weaned from positive pressure ventilation within 1 month after ASD closure. Among these 4 patients with improvement, 2 were the patients with tracheostomy; one was transitioned to tracheostomy-collar within 1 month after ASD closure (Pt 3), and the other was off positive pressure ventilation on postoperative day 4 and the tracheostomy was taken down on postoperative day 82 ( $\mathrm{Pt} 24)$. Fourteen patients were grouped as "mild to moderate," consisting of clinical symptoms of congestive heart failure including tachypnea, retractions, and/or feeding difficulties $(n=8)$; mild supplemental oxygen dependence $(n=5)$; and recurrent respiratory infections $(n=1)$. After ASD closure, 92.9\% (13/14) of mild-to-moderate respiratory symptoms resolved. Among 15 


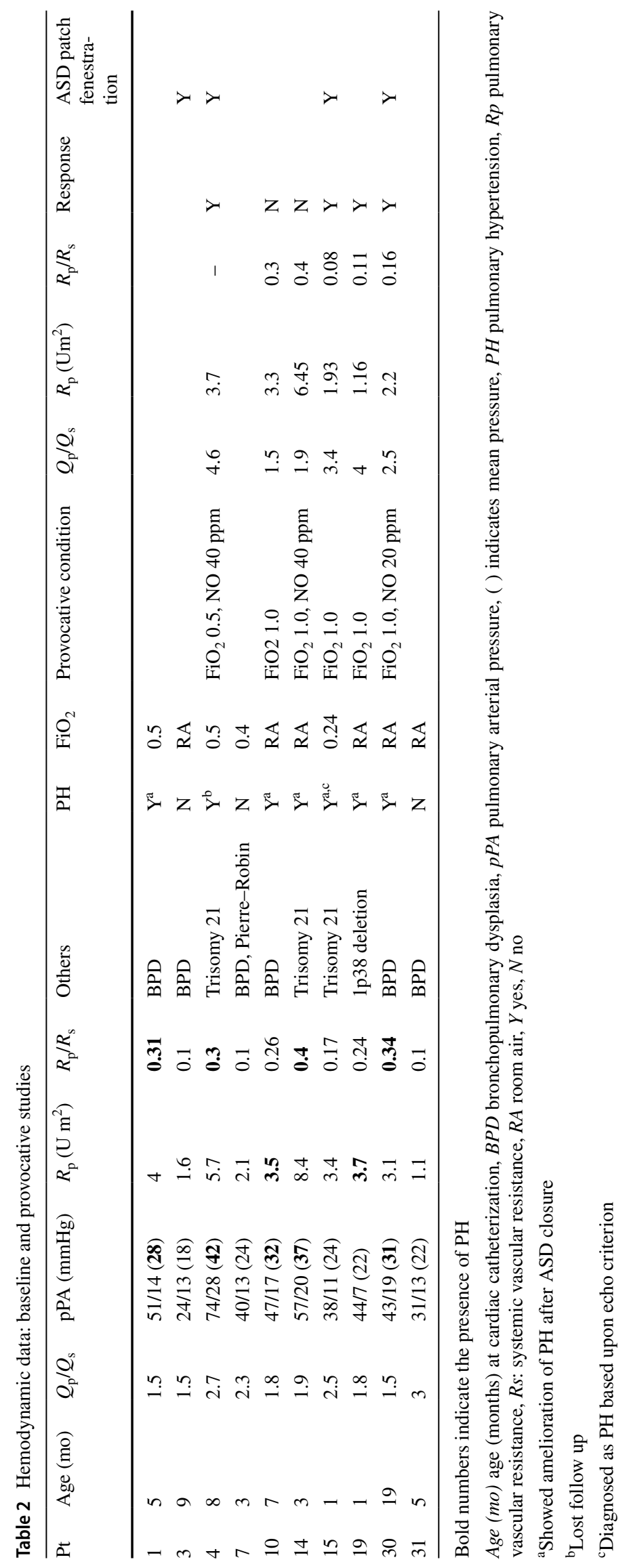


Table 3 Surgical procedures and postoperative complications

\begin{tabular}{lll}
\hline & Symptomatic ASD $(n=31)$ & $\%$ \\
\hline Materials & & \\
PTFE & 19 (3 with fenestration) & 61.3 \\
Suture & 6 & 19.4 \\
Dacron & 2 & 6.5 \\
PTFE and suture & 1 & 3.2 \\
Autologous pericardium & 4 (1 with fenestration) & 12.9 \\
Complications & & \\
Pericardial effusion & \\
Hypertension (transient) & 2 & 6.5 \\
Pleural effusion & 2 & 6.5 \\
Atrial flutter & 3 & 10 \\
SVC-RA obstruction (mild) & 1 & 3.2 \\
Seizure & 1 & 3.2 \\
Hospital days after surgery & $4-298$ days (median 8) & 3.2 \\
\hline
\end{tabular}

PTFE polytetrafluoroethylene, SVC superior vena cava, $R A$ right atrium

${ }^{a}$ Clinically significant pericardial effusion that required specific treatment including medications (corticosteroid, ibuprofen), pericardiocentesis, or creation of pericardial window

patients with improved respiratory symptoms without tracheostomy ( 2 severe and 13 mild to moderate), liberation of mechanical ventilation after the cardiac surgery occurred a median of 1 day postoperatively (ranging from $3 \mathrm{~h}$ to 15 days).

Three of 4 patients without clinical improvement in respiratory status after surgical ASD closure died of severe respiratory disease despite maximum supportive therapy (Table 4). Pt 15 was an infant with trisomy 21 with severe BPD, cystolic fibrosis, and recurrent aspiration who was ventilationdependent before ASD closure. The support was withdrawn
145 days after ASD closure, as the family declined tracheostomy and further escalation of treatment. Pt 16 was a premature, low-birth-weight infant with Pierre-Robin sequence and cleft palate who underwent tracheostomy 9 months after ASD closure for chronic respiratory failure and who never recovered from the baseline pulmonary disability and died at 6 years of age at a chronic care facility. Pt 21 was a premature infant with trisomy $21, \mathrm{BPD}$, and chronic aspiration who underwent tracheostomy 3 months after ASD closure and who died of intractable lung disease 108 days after surgery. These deaths were not directly related to postoperative complications from surgical ASD closure.

With "severe" respiratory symptoms $(n=8), 4$ patients had FTT, and 5 patients had pulmonary hypertension (Pt 3 did not have follow up evaluation as the patient was transferred back to the referring hospital after surgery). Only 2 patients in this group showed improvement in growth (50\%), whereas pulmonary hypertension was improved in all 4 patients (100\%). In the "mild-to-moderate" group $(n=14)$, 13 patients had FTT, and 3 patients had pulmonary hypertension. In this group, growth failure improved in 10/13 (76.9\%), and pulmonary hypertension showed significant improvement in all 3 patients after ASD closure.

\section{Growth Failure}

Failure to thrive improved in $15 / 24$ (62.5\%) patients (Fig. 1a). While 11/16 patients (68.8\%) with growth failure associated with respiratory symptoms improved (Table 5), $4 / 8(50 \%)$ of those without respiratory symptoms showed improvement. Among those 9 patients with FTT who did not exhibit improvement, 7 had either chromosomal or genetic abnormalities, including trisomy $21(n=3)$, Pierre-Robin

Table 4 Mortality cases

\begin{tabular}{|c|c|c|c|c|}
\hline $\mathrm{Pt}$ & Clinical information & Total hosp stay & Age of death & Cause of death \\
\hline 15 & $\begin{array}{l}\text { Trisomy } 21, \mathrm{FT} \text {, severe tracheobronchomalacia, } \mathrm{BPD}, \mathrm{CF}, \mathrm{PH} \text {, chronic aspi- } \\
\text { ration, seizure, } \\
\text { Chronic respiratory failure, FTT } \\
\text { Sinus venosus (IVC) type ASD, PDA (small) }\end{array}$ & 115 days & 5 months & Persistent respiratory failure \\
\hline 16 & $\begin{array}{l}\text { Pierre-Robin sequence, multiple congenital anomalies, cleft palate, prema- } \\
\text { turity, PH } \\
\text { Static encephalopathy, agenesis of corpus callosum, GER } \\
\text { Tracheostomy } 9 \text { months after ASD repair for worsening respiratory status, } \\
\text { chronic respiratory failure, recurrent respiratory illness, FTT } \\
\text { Secundum type ASD, mild AS (bicuspid aortic valve) }\end{array}$ & 23 days & 6 years & Cardiopulmonary arrest \\
\hline 21 & $\begin{array}{l}\text { Trisomy } 21, \text { ex- } 32 \text { wk prematurity, } \mathrm{BPD} \text {, chronic aspiration, } \mathrm{PH} \text {, } \\
\text { Hirschsprung disease } \\
\text { Tracheostomy after ASD repair for worsening respiratory status } \\
\text { Secundum type ASD }\end{array}$ & 192 days & 7 months & Persistent respiratory failure \\
\hline
\end{tabular}

$F T$ full term, $I V C$ inferior vena cava, $B P D$ bronchopulmonary dysplasia, $C F$ cystic fibrosis, $P H$ pulmonary hypertension, $P t$ patient, $F T T$ failure to thrive, IVC inferior vena cava, GER gastroesophageal reflux 
Table 5 Clinical responses to surgical ASD closure in 22 patients with variable respiratory symptoms

\begin{tabular}{|c|c|c|c|c|c|}
\hline \multirow[t]{2}{*}{$\mathrm{Pt}$} & \multirow[t]{2}{*}{ Diagnosis } & \multicolumn{4}{|c|}{ Improvement in } \\
\hline & & DOS & Respiratory Symptoms & FTT & $\mathrm{PH}$ \\
\hline \multicolumn{6}{|c|}{ [1] Severe: Ventilator-dependent chronic respiratory failure $(n=8)$} \\
\hline 1 & Ex-27w, BPD, laryngomalacia, GER. PH & 162 & $\begin{array}{l}\text { Y: Extubated }\left(3 \text { days }^{\mathrm{d}}\right) \text {, off suppl. oxygen } \\
\left(7 \text { days }^{\mathrm{d}}\right)\end{array}$ & - & $\mathrm{Y}$ \\
\hline 3 & Ex-24w, BPD, tracheobronchomalacia, subglottic stenosis, Trach & 290 & Y: Off vent 1 month after surgery & - & $\mathrm{b}$ \\
\hline 7 & Ex-32w, BPD, Pierre-Robin sequence, cleft palate, Trach & 104 & $\mathrm{~N}$ & $\mathrm{Y}$ & - \\
\hline 12 & $\begin{array}{l}\text { Chr } 3 / 4 \text { translocation, spastic quadriplegia, seizure, multiple congenital } \\
\text { anomalies }\end{array}$ & 379 & Y: Extubated $\left(15\right.$ days $\left.^{\mathrm{d}}\right)$ & $\mathrm{Y}$ & - \\
\hline 15 & Trisomy 21, BPD, PH, severe laryngomalacia, seizures, CF, FTT & 63 & $\mathrm{~N}^{\mathrm{a}}$ & $\mathrm{N}$ & $\mathrm{Y}^{\mathrm{c}}$ \\
\hline 16 & $\begin{array}{l}\text { Multiple congenital anomalies, Pierre-Robin sequence, prematurity, } \mathrm{PH} \text {, } \\
\text { apnea }\end{array}$ & 54 & $\mathrm{~N}^{\mathrm{a}}$ & $\mathrm{N}$ & $Y^{c}$ \\
\hline 21 & Ex-32w, BPD, trisomy 21, Trach, aspiration, Hirschsprung disease & 81 & $\mathrm{~N}^{\mathrm{a}}$ & - & $\mathrm{Y}^{\mathrm{c}}$ \\
\hline 24 & $\begin{array}{l}\text { CODAS syndrome, Trach, imperforate anus, congenital skeletal anoma- } \\
\text { lies }\end{array}$ & 409 & Y: Off vent $\left(4\right.$ days $\left.^{\mathrm{d}}\right)$ & - & - \\
\hline \multicolumn{6}{|c|}{ [2] Mild to moderate $(n=14)$} \\
\hline \multicolumn{6}{|c|}{ (1) CHF symptoms (tachypnea, poor feeding, and retraction) $(n=8)$} \\
\hline 8 & Mild arch hypoplasia, CHF, FTT & 339 & $\mathrm{Y}$ & $\mathrm{Y}$ & - \\
\hline 9 & Ex-27w, BPD, mild arch hypoplasia, CHF, FTT & 193 & $\mathrm{Y}$ & $\mathrm{Y}$ & - \\
\hline 11 & Ex-31w, BPD, twin, CHF, FTT & 251 & $\mathrm{Y}$ & $\mathrm{Y}$ & - \\
\hline 13 & Trisomy 21, CHF, FTT, PH & 162 & $\mathrm{Y}$ & $\mathrm{N}$ & - \\
\hline 18 & Mild PS, tachypnea, CHF, FTT & 121 & $\mathrm{Y}$ & $\mathrm{Y}$ & - \\
\hline 19 & Ex-37w, IUGR (BW 1.76 kg), 1p36 del, CHF, PH & 60 & $\mathrm{Y}$ & - & $\mathrm{Y}$ \\
\hline 22 & PAPVR with sinus venosus type ASD, congenital CMV, CHF, FTT & 105 & $\mathrm{Y}$ & $\mathrm{Y}$ & - \\
\hline 23 & Ex-34w, BPD, tachypnea, CHF, FTT & 123 & Y & $\mathrm{Y}$ & - \\
\hline \multicolumn{6}{|c|}{ (2) Supplemental oxygen $(n=5)$} \\
\hline 10 & Ex-29w BPD, CHF, PH, GER, aspiration, oxygen-dependent & 232 & Y: Off suppl. oxygen & $\mathrm{Y}$ & $\mathrm{Y}$ \\
\hline 14 & Trisomy 21, small transverse arch, FTT, CHF, PH & 114 & $\mathrm{~N}$ & $\mathrm{~N}$ & $\mathrm{Y}$ \\
\hline 20 & Ex-26w, BPD, CHF, FTT & 158 & Y: Off suppl. oxygen & $\mathrm{Y}$ & - \\
\hline 26 & Ex-30w, BPD, FTT & 385 & Y: Off suppl. oxygen & $\mathrm{Y}$ & - \\
\hline 28 & Trisomy 21, CLD, history of PPHN, FTT & 237 & Y: Off suppl. oxygen & $\mathrm{Y}$ & - \\
\hline \multicolumn{6}{|c|}{ (3) Recurrent infections $(n=1)$} \\
\hline \multirow[t]{2}{*}{17} & $\begin{array}{l}\text { Ex-35w, BPD, Kabuki syndrome, GER, recurrent respiratory infections, } \\
\text { FTT }\end{array}$ & 33 & Y: No recurrence of infection & $\mathrm{N}$ & - \\
\hline & & & $17 / 22$ & $12 / 16$ & $7 / 7$ \\
\hline
\end{tabular}

Bold words are for emphasis of trache (tracheostomy)

DOS days (post-natal) of surgery, BPD bronchopulmonary dysplasia, GER gastroesophageal reflux, suppl. supplemental, Chr chromosome, Trach tracheostomy, $P H$ pulmonary hypertension, $F T T$ failure to thrive, $C H F$ congestive heart failure, $C M V$ cytomegalovirus, $P S$ pulmonary stenosis, $P A P V R$ partial anomalous of pulmonary venous return, $C L D$ chronic lung disease (without premature lung), $Y$ yes, $N$ no

${ }^{a}$ Deceased (see Table 5), ${ }^{b}$ had pulmonary hypertension but was lost to follow up after surgery, ${ }^{\mathrm{c}}$ diagnosed by echocardiogram only, ${ }^{\mathrm{d}}$ after surgical ASD closure

sequence $(n=1)$, Kabuki syndrome $(n=1)$, or unknown syndromic disorder $(n=2)$, but 2 did not have any clinical features suggestive of underlying genetic abnormalities.

\section{Pulmonary Hypertension}

Pulmonary hypertension was diagnosed by cardiac catheterization $(n=6$, see Table 2$)$ or echocardiogram ( $n=3$; Pts 15,16 , and 21, see Table 5). Predicted systolic pulmonary arterial pressure estimated by TR jet velocity decreased to less than half systolic in 7 out of $7(100 \%$, Fig. 1b) patients with pulmonary hypertension following ASD closure. One patient (Pt 4, Table 2) was lost to follow up, and the other (Pt 30) did not have sufficient tricuspid valve regurgitation in postoperative echocardiogram. In 2 patients with preoperative catheterization demonstrating elevated and relatively unchanged pulmonary vascular resistance (Pts 10 and 14 in Table 2), there was a significant reduction in RV 
A

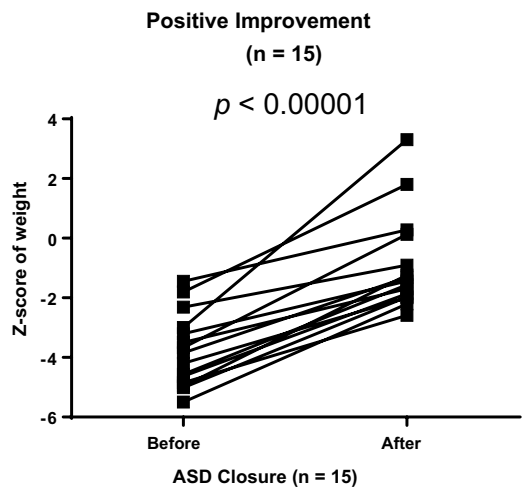

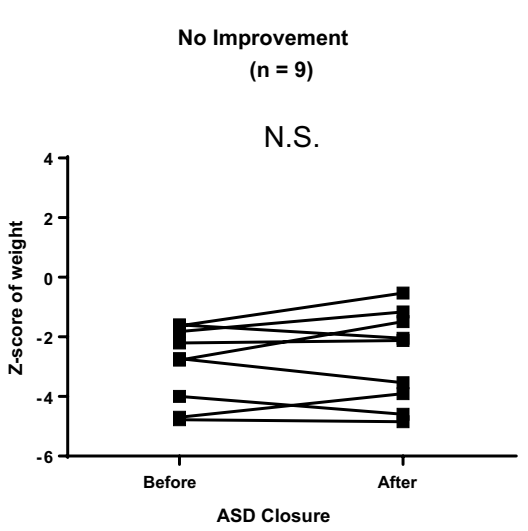

B

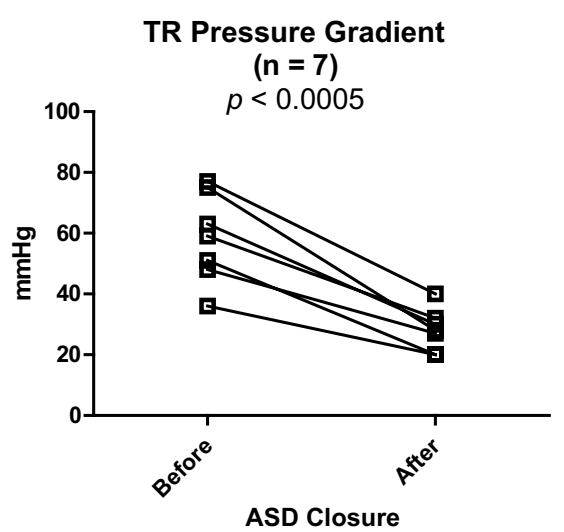

Fig. 1 a Resumption of normal physical growth after ASD closure. $Y$ axis represents $z$ score of body weight at standard growth chart (CDC 0 to 36 months, male or female). Positive trend was noted in 15 patients (left; $z$ score from $-3.8 \pm 1.2$ to $-0.9 \pm 1.6$ : $p<0.00005$ ), whereas there was no improvement in 7 patients (right; $z$ score from $-2.9 \pm 1.3$ to $-2.7 \pm 1.6$ ). One patient in the nonresponsive group was not included because the patient died 3 months after ASD clo-

pressure after ASD closure. Both patients received inhaled nitric oxide immediately after surgery and were discharged home with oral sildenafil, whereas only Pt 14 with trisomy 21 and elevated $\mathrm{Rp}\left(8.4\right.$ units $\cdot \mathrm{m}^{2}$ ) underwent ASD patch closure with fenestration. Even in the 3 patients who died after surgery because of progressive lung disease (Table 4), preoperatively noted elevated pulmonary arterial pressure was significantly reduced after ASD closure without specific pulmonary vasodilator treatment.

\section{Discussion}

This study demonstrates that early surgical ASD closure can be beneficial for symptomatic patients with underlying pulmonary abnormalities, especially those with BPD. In fact, among the patients with ventilator-dependent chronic respiratory failure, half of them improved sufficiently to achieve liberation from ventilator support. It should be noted that the beneficial effects of eliminating the excessive pulmonary blood flow did outweigh the open heart surgery-related morbidity and mortality even among patients with the most severe forms of pulmonary disease. Similarly, growth retardation was improved in most of the patients without underlying genetic abnormalities. Finally, ASD closure resulted in reduction of estimated RV pressure by echocardiogram in all cases with pulmonary hypertension. sure (Pt 15). b Improvement of pulmonary hypertension $(\mathrm{PH})$ after ASD closure. $Y$ axis represents pressure gradient $(\mathrm{mmHg})$ of tricuspid regurgitation (TR) jet assessed by continuous pulse Doppler method before and after ASD closure. Postoperative echocardiogram was performed within 6 months after surgery. All 7 patients showed significant decrease in TR pressure gradient $(62.8 \pm 14.8$ to $29 \pm 7.0 \mathrm{mmHg}$; $p<0.005)$

\section{ASD Closure Resulted in Significant Clinical Improvement in Symptomatic Patients Younger Than 2 Years of Age}

Patients with isolated ASD usually remain asymptomatic throughout childhood and early adulthood despite increased pulmonary blood flow and RV volume overload. However, the patients with ASD may become symptomatic in combination with decreased left ventricular compliance, marginal left heart structure, or left ventricular dysfunction [15]. Increased pulmonary blood flow as a result of ASD may lead to deleterious effects on those patients with lung diseases related to prematurity, BPD, and recurrent aspiration and may be responsible for significant morbidity and mortality [16]. In our study, $80.6 \%$ of patients with respiratory symptoms had resolution after ASD closure (50\% in severe cases and $92.9 \%$ in mild-to-moderate cases). Four of 5 patients who did not respond to ASD closure were those with advanced pulmonary disease with ongoing complex medical problems (Pts 7, 15, 16, and 21 in Table 5). Three of these 4 patients died (Table 4). Earlier surgery might have been beneficial for those patients with ASD and worsening respiratory status. For clinically complicated patients, the defect is best closed sooner to prevent the development of further pulmonary vascular damage and perhaps may improve their clinical condition $[6,17]$. 


\section{Post-surgical Clinical Improvement is Determined by Underlying Pulmonary Status}

Our data suggest that reducing pulmonary blood flow by ASD closure effectively improved pulmonary mechanics in the majority of symptomatic patients with underlying lung disease, especially with BPD, as is commonly seen in closing PDA in these patients [18]. Reduction in pulmonary blood flow by closing ASD may facilitate natural improvement of BPD over time [18]. Resumption of normal growth was noted more frequently in the patients with respiratory symptoms. This finding is, in part, in agreement with the previous observation that non-cardiac reasons were frequently responsible for FTT in infants with ASD not associated with significant respiratory symptoms $[19,20]$.

Pulmonary hypertension was significantly reduced after surgical ASD closure in nearly all patients, as was previously reported [7, 21-23]. The patients with increased risk of postoperative pulmonary hypertension were managed with inhaled nitric oxide and/or sildenafil with favorable outcome. Fenestrated patch was applied in two cases with pulmonary hypertension (Pts 2 and 30) to prevent potential pulmonary hypertensive crisis. We did not encounter any cases with severe pulmonary vascular obstructive disease, as reported by others $[17,20]$. According to the current American and European guidelines, ASD can be safely closed if $R_{\mathrm{p}} / R_{\mathrm{S}}<1 / 3$ or $Q_{\mathrm{p}} / Q_{\mathrm{s}}>1.5$ [24, 25], but the surgical indications may be further liberated as there are more pulmonary vasodilators available in recent years [26]. Careful preoperative hemodynamic evaluation with or without preoperative medical treatment is warranted for all patients with severe pulmonary hypertension beyond these indications.

\section{Surgical ASD Closure Can be Performed Safely in Symptomatic Young Children}

Surgical closure of ASD in the contemporary era can be safely accomplished in younger children with similar or lower incidence of complications as reported in older children $[3,27,28]$. Pericardial effusion after surgical ASD closure is reported to be less frequent in infants or younger children than in older children [28-30]. The incidence of postoperative complications in symptomatic patients in our study (Table 3) is comparable to what has been reported in older asymptomatic patients [28-30]. Indeed, some sick infants with progressively worsening respiratory status (Pts 1 and 3 in Table 5) showed compelling clinical improvement after surgical ASD closure without postoperative complications. Due to significant improvement of intensive care management after open heart surgery in sick infants, the benefit of preventing chronic pulmonary complications by surgical ASD closure in young patients with underlying pulmonary abnormalities may prevail over the risk of potential shortterm surgical complications when the patients are not clinically improving despite maximum medical treatment and when percutaneous ASD device closure is not indicated.

During the same period of time, we have performed transcatheter device closure in 22 symptomatic ASD patients younger than 2 years $(356 \pm 200$ days; 10 males and 12 females) who also had postoperative assessment at least for a year (unpublished data). Ten patients were former premature infants, 2 were trisomy 21, and one had multiple congenital anomalies. Clinical indications for ASD closure include respiratory symptoms $(n=15)$, FTT $(n=10)$, pulmonary hypertension $(n=9)$, and multiple cerebral infarcts $(n=1)$. With ASD device closure, improvement of respiratory status, growth, and estimated pulmonary arterial pressure was noted in 60\% (9/15), 40\% (4/10), and 100\% (9/9), respectively, which are essentially similar to the results after surgical ASD closure in this study. Collectively, our current data indicate that the elimination of excessive pulmonary blood flow by closing ASD in symptomatic infants and young children helps improve homodynamic status and ameliorate clinical symptoms regardless of the therapeutic modalities.

\section{Limitations}

There are several limitations in this study. First, this is a retrospective study in a single institution with a relatively small number of the patients with heterogenous backgrounds. Secondly, all symptomatic infants and young children with ASD underwent ASD closure in our hospital. Thus, there were no control symptomatic patients who were solely managed non-surgically without ASD closure. Instead, we compared the 3 clinical parameters before and after ASD closure and assessed the outcomes in an objective manner. Thirdly, pulmonary hypertension was not strictly defined in this study, and not all patients underwent diagnostic catheterization. Only 6 patients were diagnosed with pulmonary hypertension by cardiac catheterization, and 3 patients were diagnosed by echocardiogram only. Improvement of pulmonary hypertension was assessed only by decrease in echocardiographic measurement of estimated RV pressure, not by decrease in pulmonary vascular resistance. Lastly, there were 3 symptomatic ASD patients with small unclosed PDA. Although these PDAs were small, we cannot underestimate a significant contribution of PDA ligation to the observed improvement. 


\section{Conclusion}

We have demonstrated that early ASD closure in infants and young children with underlying chronic lung disease may improve respiratory symptoms and overall clinical outcomes. Surgical ASD closure can be performed safely in symptomatic infants and young children with no significant incidence in perioperative morbidity and mortality. We suggest early closure of ASD, either by device or by surgery, in all symptomatic infants and young toddlers with underlying chronic lung disease to mitigate ongoing parenchymal and vascular injury to the lung while enhancing improvement of lung function.

Acknowledgements We thank Dr. William Norwood for his important contribution in the care of some of these patients and Dr. Samuel Gidding for his critical reading and valuable suggestions while preparing this manuscript.

\section{Compliance with Ethical Standards}

Conflict of interest The authors declare that they have no conflict ofinterest.

\section{References}

1. Geva T, Martins JD, Wald RM (2014) Atrial septal defects. Lancet 383:1921-1932

2. Webb G, Gatzoulis MA (2006) Atrial septal defects in the adult: recent progress and overview. Circulation 114:1645-1653

3. Roos-Hesselink JW, Meijboom FJ, Spitaels SE, van Domburg R, van Rijen EH, Utens EM, Bogers AJ, Simoons ML (2003) Excellent survival and low incidence of arrhythmias, stroke and heart failure long-term after surgical ASD closure at young age. A prospective follow-up study of 21-33 years. Eur Heart J 24:190-197

4. Bull C, Deanfield J, de Leval M, Stark J, Taylor JF, Macartney FJ (1981) Correction of isolated secundum atrial septal defect in infancy. Arch Dis Child 56:784-786

5. Hunt CE, Lucas RV Jr (1973) Symptomatic atrial septal defect in infancy. Circulation 47:1042-1048

6. Phillips SJ, Okies JE, Henken D, Sunderland CO, Starr A (1975) Complex of secundum atrial septal defect and congestive heart failure in infants. J Thorac Cardiovasc Surg 70:696-700

7. Lammers A, Hager A, Eicken A, Lange R, Hauser M, Hess J (2005) Need for closure of secundum atrial septal defect in infancy. J Thorac Cardiovasc Surg 129:1353-1357

8. Riggs T, Sharp SE, Batton D, Hussey ME, Weinhouse E (2000) Spontaneous closure of atrial septal defects in premature vs. full-term neonates. Pediatr Cardiol 21:129-134

9. Mahoney LT, Truesdell SC, Krzmarzick TR, Lauer RM (1986) Atrial septal defects that present in infancy. Am J Dis Child 140:1115-1118

10. Cockerham JT, Martin TC, Gutierrez FR, Hartmann AF Jr, Goldring D, Strauss AW (1983) Spontaneous closure of secundum atrial septal defect in infants and young children. Am J Cardiol 52:1267-1271
11. Du ZD, Hijazi ZM, Kleinman CS, Silverman NH, Larntz K, Amplatzer I (2002) Comparison between transcatheter and surgical closure of secundum atrial septal defect in children and adults: results of a multicenter nonrandomized trial. J Am Coll Cardiol 39:1836-1844

12. Cardenas L, Panzer J, Boshoff D, Malekzadeh-Milani S, Ovaert C (2007) Transcatheter closure of secundum atrial defect in small children. Catheter Cardiovasc Interv 69:447-452

13. Wyss Y, Quandt D, Weber R, Stiasny B, Weber B, Knirsch W, Kretschmar O (2016) Interventional closure of secundum type atrial septal defects in infants less than 10 kilograms: indications and procedural outcome. J Interv Cardiol 29:646-653

14. Ohno N, Chaturvedi R, Lee KJ, Benson L (2015) Characteristics of secundum atrial septal defects not percutaneously closed. Catheter Cardiovasc Interv 85:234-239

15. Kingma SD, Rammeloo LA, Sojak V, Hruda J (2012) Small atrial septal defect associated with heart failure in an infant with a marginal left ventricle. Clin Pract 2:e69

16. Joshi NC, Dalvi R, Merchant RH (1993) Symptomatic atrial septal defect in infancy. Indian Pediatr 30:1079-1083

17. Haworth SG (1983) Pulmonary vascular disease in secundum atrial septal defect in childhood. Am J Cardiol 51:265-272

18. del Cerro MJ, Sabate Rotes A, Carton A, Deiros L, Bret M, Cordeiro M, Verdu C, Barrios MI, Albajara L, Gutierrez-Larraya $\mathrm{F}$ (2014) Pulmonary hypertension in bronchopulmonary dysplasia: clinical findings, cardiovascular anomalies and outcomes. Pediatr Pulmonol 49:49-59

19. Mainwaring RD, Mirali-Akbar H, Lamberti JJ, Moore JW (1996) Secundum-type atrial septal defects with failure to thrive in the first year of life. J Card Surg 11:116-120

20. Andrews R, Tulloh R, Magee A, Anderson D (2002) Atrial septal defect with failure to thrive in infancy: hidden pulmonary vascular disease? Pediatr Cardiol 23:528-530

21. Goetschmann S, Dibernardo S, Steinmann H, Pavlovic M, Sekarski N, Pfammatter JP (2008) Frequency of severe pulmonary hypertension complicating "isolated" atrial septal defect in infancy. Am J Cardiol 102:340-342

22. Huang ZW, Fan ZX, Sun JT, Li WM, Gao YQ, Quan YH, Geng YM, Niu YY, Wu BX (2012) The short- and medium-term results of transcatheter closure of atrial septal defect with severe pulmonary arterial hypertension. Heart Vessels 27:603-609

23. Lee JS, Cha SG, Kim GB, Lee SY, Song MK, Kwon HW, Bae EJ, Kwak JG, Kim WH, Lee JR (2019) Reversibility of pulmonary hypertension following surgical atrial septal defect closure in children with down syndrome. J Cardiovasc Imaging 27:247-253

24. Warnes CA, Williams RG, Bashore TM, Child JS, Connolly HM, Dearani JA, Del Nido P, Fasules JW, Graham TP Jr, Hijazi ZM, Hunt SA, King ME, Landzberg MJ, Miner PD, Radford MJ, Walsh EP, Webb GD (2008) ACC/AHA 2008 guidelines for the management of adults with congenital heart disease: a report of the American College of Cardiology/American Heart Association Task Force on Practice Guidelines (Writing Committee to Develop Guidelines on the Management of Adults With Congenital Heart Disease). Developed in Collaboration with the American Society of Echocardiography, Heart Rhythm Society, International Society for Adult Congenital Heart Disease, Society for Cardiovascular Angiography and Interventions, and Society of Thoracic Surgeons. J Am Coll Cardiol 52:e143-e263

25. Baumgartner H, Bonhoeffer P, De Groot NM, de Haan F, Deanfield JE, Galie N, Gatzoulis MA, Gohlke-Baerwolf C, Kaemmerer H, Kilner P, Meijboom F, Mulder BJ, Oechslin E, Oliver JM, Serraf A, Szatmari A, Thaulow E, Vouhe PR, Walma E, Task Force on the Management of Grown-up Congenital Heart 
Disease of the European Society of Cardiology, Association for European Paediatric Cardiology, Guidelines ESCCfP (2010) ESC guidelines for the management of grown-up congenital heart disease (new version 2010). Eur Heart J 31:2915-2957

26. Galie N, Humbert M, Vachiery JL, Gibbs S, Lang I, Torbicki A, Simonneau G, Peacock A, Vonk Noordegraaf A, Beghetti M, Ghofrani A, Gomez Sanchez MA, Hansmann G, Klepetko W, Lancellotti P, Matucci M, McDonagh T, Pierard LA, Trindade PT, Zompatori M, Hoeper M, Group ESCSD (2016) 2015 ESC/ ERS Guidelines for the diagnosis and treatment of pulmonary hypertension: The Joint Task Force for the Diagnosis and Treatment of Pulmonary Hypertension of the European Society of Cardiology (ESC) and the European Respiratory Society (ERS): Endorsed by: Association for European Paediatric and Congenital Cardiology (AEPC), International Society for Heart and Lung Transplantation (ISHLT). Eur Heart J 37:67-119

27. Galal MO, Wobst A, Halees Z, Hatle L, Schmaltz AA, Khougeer F, De Vol E, Fawzy ME, Abbag F, Fadley F et al (1994) Peri-operative complications following surgical closure of atrial septal defect type II in 232 patients - a baseline study. Eur Heart J 15:1381-1384

28. Jones DA, Radford DJ, Pohlner PG (2001) Outcome following surgical closure of secundum atrial septal defect. J Paediatr Child Health 37:274-277

29. Baskett RJ, Tancock E, Ross DB (2003) The gold standard for atrial septal defect closure: current surgical results, with an emphasis on morbidity. Pediatr Cardiol 24:444-447

30. Heching HJ, Bacha EA, Liberman L (2015) Post-pericardiotomy syndrome in pediatric patients following surgical closure of secundum atrial septal defects: incidence and risk factors. Pediatr Cardiol 36:498-502

Publisher's Note Springer Nature remains neutral with regard to jurisdictional claims in published maps and institutional affiliations. 